\title{
Correlations between imagery and memory across stimuli and across subjects
}

\author{
JOHN T. E. RICHARDSON \\ Brunel University, Uxbridge, Middlesex UB8 $3 P H$, England
}

\begin{abstract}
Stimulus imageability has been reliably established as an excellent predictor of memory performance. Variation among subjects in evoked mental imagery shows no such correlation with recall. Two experiments showed these generalizations to hold even when correlations across stimuli and across subjects were computed from the same data. It was concluded that ratings of the subjective vividness of evoked mental imagery are not valid indexes for research on individual differences in memory performance.
\end{abstract}

Under a wide variety of experimental conditions, it has been reliably established that the image-arousing potential of the stimulus material is highly correlated with its memorability. Indeed, Paivio (1971, Chapter 7) concluded that imageability was the best predictor of performance of all the stimulus attributes investigated by experimental psychologists. This is in marked contrast to the failure of studies of the variation among individual subjects to demonstrate a reliable correlation between evoked mental imagery and memory performance. In this paper, I shall attempt to resolve this fundamental discrepancy in the experimental evidence for the importance of mental imagery as a psychological process.

Stimulus imageability is measured by the use of questionnaires administered to large groups of subjects, in which they are asked to evaluate items along 7-point rating scales. Such questionnaires customarily employ instructions similar to those used by Paivio, Yuille, and Madigan (1968), who defined an item's imagery value as the ease with which it aroused a mental image. This value is computed by taking the average rating across the subjects employed in the rating task.

The imagery ability of an individual subject may be measured either by the use of questionnaires on the subjective vividness of experienced imagery or by tests of spatial manipulation ability (Ernest, 1977). When careful experimental procedures are employed to avoid experimenter bias and other sources of variation in demand characteristics, neither method shows any correlation between imagery ability and memory performance (Berger \& Gaunitz, 1977; Richardson, 1978a). This is puzzling, since the questionnaires on the vividness of experienced imagery are at least superficially quite similar to the rating tasks used to measure stimulus imageability. The subjects are once again asked to evaluate the ease with which various items arouse vivid mental imagery, and a subject's imagery ability is measured by

Requests for reprints should be sent to Dr. J. T. E Richardson, Department of Psychology, Brunel University, Uxbridge, Middlesex UB8 3PH, England. taking the average rating across the stimuli employed (e.g., Sheehan, 1967).

One possible explanation is that the apparent similarity between the two tasks hides crucial procedural differences that prevent variation among subjects in evoked mental imagery from having predictive capacity in investigations of human memory. This can be easily tested by obtaining measures of stimulus imageability and subject imagery ability within the same experimental situation and considering the correlations between these measures and subsequent memory performance. If both indexes are valid measures of variation in evoked mental imagery, they should be equally successful in predicting recall. This idea is tested in Experiment 1 .

On the other hand, a more radical suggestion may be made. It could be argued that mental imagery is essentially private and solipsistic (e.g., Doob, 1972). In particular, it is likely that subjects lack a definite origin and a definite unit of measurement for making these subjective judgments, and that, in consequence, their appreciation of the vividness of mental imagery can be taken to define at best an ordinal scale. It is possible that such judgments are adequate to ensure that relatively gross comparisons among different stimulus items predict variations in the memorability of those items. Nevertheless, since there is no unique mapping of this ordinal subjective scale of vividness onto the 7-point rating scale (which may be variously interpreted as representing either an interval scale or a ratio scale), the absolute values assigned by a subject to a given stimulus will have no meaning, and comparisons among different subjects in terms of their average ratings will not predict variations in memory performance. Therefore, even if measures of stimulus imageability and subject imagery ability are obtained within the same experimental situation, the former may predict recall performance, but the latter should not.

\section{EXPERIMENT 1}

\section{Method}

Twenty-seven students participating in an introductory course in laboratory methods at Brunel University were asked to 
evaluate 40 English nouns with frequencies of $\mathrm{AA}$ or $\mathrm{A}$ in the count of Thorndike and Lorge (1944). The items were presented for rating on imageability following the procedure of Paivio, Yuille, and Madigan (1968). The subjects received a response booklet, the first page of which contained instructions for giving imagery ratings, with four additional nouns as examples. The second page contained 40 7-point rating scales. The ends of each scale were labeled "low imagery" and "high imagery," and each scale was numbered from 1 to 40 . When all of the subjects had read the instructions, they turned to the second page of the response booklet. The words were read aloud by the experimenter at a rate of one item every $10 \mathrm{sec}$, and the subjects responded by rating each item on the 7-point scale. After they had rated the last item, the subjects received an unanticipated recall test on the 40 items. They received standard free recall instructions, their responses were written on the reverse of the response booklet, and they were allowed $3 \mathrm{~min}$ for recall.

\section{Results}

Data from the first five items and the last five items were ignored to avoid primacy and recency effects in recall. Thus, rating and recall data were employed from 30 items and from 27 subjects. The average recall per subject was 9.81 items, and the average imagery rating was 4.55 .

The first analysis considered the effect of stimulus imageability upon recall. The correlation between the mean imagery rating assigned to each item and the proportion of subjects who recalled that item was +.28 . This approached, but did not attain, statistical significance by a one-tailed test $[\mathrm{t}(28)=1.56, .1>\mathrm{p}>.05]$.

The second analysis considered the effect of the subjects' imagery ability upon recall. The correlation between the mean imagery rating given by each subject and the proportion of items recalled by that subject was -.07 . A one-tailed $t$ test showed that this was not at all significant $[\mathrm{t}(25)=-.33, \mathrm{p}>.6]$.

\section{Discussion}

The results of this experiment show the usual positive (although here, nonsignificant) relationship between stimulus imageability and recall; on the other hand, there was no sign of a correlation between the subjects' imagery ability and recall. The experiment can therefore be taken to provide support for the view that comparisons between subjects in their ratings of evoked mental imagery are not meaningful.

It might be objected, however, that this experiment has failed to discriminate between subject comparisons and item comparisons as possible predictors of memory performance, since neither correlation reached statistical significance. The effect of stimulus imageability is typically more pronounced than that obtained here, and it might be argued that the experiment was simply not a sensitive test of the predictive capacity of either sort of comparison. In fact, it is likely that the procedure employed was not insensitive, but merely inappropriate. It is well known that mental imagery is of particular value in remembering associative connections among stimulus items and that inducing images of individual items is not an appropriate way of investigating the value of mental imagery as a mnemonic code (Bower, 1972; Richardson, 1976). This might explain the continued failure to find a correlation between memory performance and subjective imagery ability, since the latter is typically assessed by questionnaires in which subjects are asked to rate the vividness of images evoked by individual stimulus items. It is not a very plausible explanation, since the vividness of the image evoked by an individual item is likely to be correlated with the vividness of the image evoked by a set of stimuli that includes that item, and, of course, ratings of individual items do predict the memorability of those items in other experimental tasks. Nevertheless, it has particular force as an objection to the adequacy of Experiment 1, which was essentially an incidental learning study, in which the sole orienting task involved the creation of separative mental imagery. The following experiment responded to this objection, by considering stimulus imageability and subject imagery ability as predictors of recall in a task designed to induce interactive mental imagery (cf. Bower, 1972).

\section{EXPERIMENT 2}

\section{Method}

Twenty-five students participating in an introductory course in laboratory methods at Brunel University were asked to evaluate 40 pairs of words, consisting of 80 English nouns with a frequency of AA or A (Thorndike \& Lorge, 1944), assigned to pairs in a random fashion. The items were presented for rating on imageability following the procedure of Paivio, Yuille, and Madigan (1968). The first page of the response booklet contained instructions for giving imagery ratings, with four additional pairs of nouns as examples; the subjects were asked to rate the ease with which each pair aroused a mental image in which the two things were interrelated or interacting in some way. The second page contained 407 -point rating scales, as in Experiment 1. The third page contained the first members of 30 of the pairs, excluding the first 5 and the last 5 as filler items to remove the primacy and recency effects in recall; these stimulus terms were listed in a single column in a new random order.

When all of the subjects had read the instructions, they turned to the second page of the response booklet. The pairs of words were read aloud by the experimenter at a rate of one pair every $10 \mathrm{sec}$, and the subjects responded by rating each pair on the 7-point scale.

After they had rated the last pair, the subjects received an unanticipated recall test on the 30 critical pairs. They turned to the third page of the response booklet and were asked to provide the correct response term for each of the 30 stimulus terms shown. Responses were written, and $5 \mathrm{~min}$ was allowed for recall.

\section{Results}

Rating and recall data were employed from 30 pairs and from 25 subjects. The average recall per subject was 13.08 pairs, and the average imagery rating was 4.66 .

The first analysis considered the effect of stimulus imageability upon recall. The correlation between the mean imagery rating assigned to each pair and the proportion of subjects who recalled that pair was +.67 . A one-tailed t test showed that this was highly significant $[\mathrm{t}(28)=4.83, \mathrm{p}<.001]$.

The second analysis considered the effect of the subjects' imagery ability upon recall. The correlation between the mean imagery rating given by each subject and the proportion of pairs recalled by that subject was +.12 . A one-tailed t test showed that this was not at all significant $[\mathrm{t}(23)=.59, \mathrm{p}>.25]$.

\section{Discussion}

The results of this experiment extended and clarified those of Experiment 1. There was a substantial and significant relationship between stimulus imageability and recall in an incidental paired associate task. This merely replicated the findings 
of earlier research (Bower, 1972) However, once again, there was no sign of a correlation between the subjects' imagery ability and recall. This study has therefore produced sound evidence that comparisons between subjects in terms of their ratings of evoked mental imagery are neither valid nor meaningful. One may reject the suggestion that procedural differences are responsible for discrepancies between previous research on individual difference and on stimulus attributes concerning the role of mental imagery in human memory.

One should not conclude, however, that all introspective evidence on mental imagery is equally invalid or unhelpful (cf. Bower, 1970). The present findings on ratings of the subjective vividness of experienced imagery are in clear opposition to the results obtained with postlearning questionnaires to elicit the nature of subjects' mediators in learning. These studies have obtained a substantial correlation between the incidence of imaginal mediators and recall performance both across stimulus items (Paivio, Smythe, \& Yuille, 1968; Paivio, Yuille, \& Smythe, 1966) and across individual subjects (Richardson, 1978b). Future research must attempt to identify more clearly those questions that may be meaningfully addressed to subjects in psychological experiments concerning mental imagery.

\section{REFERENCES}

Berger, G. H., \& Gaunitz, S. C. B. Self-rated imagery and vividness of task pictures in relation to visual memory. British Journal of Psychology, 1977, 68, 283-288.

Bowe R, G. H. Analysis of a mnemonic device. American Scientist, 1970, 58, 496-510.

Bower, G. H. Mental imagery and associative learning. In L. W. Gregg (Ed.), Cognition in learning and memory. New York: Wiley, 1972.

DooB, L. W. The ubiquitous appearance of images. In P. W.
Sheehan (Ed.), The function and nature of imagery. New York: Academic Press, 1972.

ERNEST, C. H. Imagery ability and cognition: A critical review. Journal of Mental Imagery, 1977, 1, 181-216.

PAIvio, A. Imagery and verbal processes. New York: Holt, Rinehart, \& Winston, 1971

Paivio, A., Smythe, P. C., \& Yuille, J. C. Imagery versus meaningfulness of nouns in paired-associate learning. Canadian Journal of Psychology, 1968, 22, 427-441.

Paivio, A., Yuille, J. C., \& Madigan, S. A. Concreteness, imagery, and meaningfulness values for 925 nouns. Journal of Experimental Psychology Monograph, 1968, 76(1, Pt. 2).

Paivio, A., Yuille, J. C., \& Sm Ythe, P. C. Stimulus and response abstractness, imagery, and meaningfulness, and reported mediators in paired-associate learning. Canadian Journal of Psychology, 1966, 20, 362-377.

Richardson, J. T. E. Procedures for investigating imagery and the distinction between primary and secondary memory. British Journal of Psychology, 1976, 67, 487-500.

Richardson, J. T. E. Mental imagery and memory: Coding ability or coding preference? Journal of Mental Imagery, 1978, 2, 101-115. (a)

Richardson, J. T. E. Reported mediators and individual differences in mental imagery. Memory \& Cognition, 1978, 6, 376378. (b)

SheEhan, P. W. A shortened form of Betts' questionnaire upon mental imagery. Journal of Clinical Psychology, 1967, 23, 386389.

Thorndike, E. L., \& LoRge, I. The teacher's word book of 30,000 words. New York: Teachers College, Columbia University, 1944.

(Received for publication August 28, 1979.) 